\title{
Spinal Matrix Metalloproteinase-9 Contributes to Physical Dependence on Morphine in Mice
}

\author{
Wen-Tao Liu, ${ }^{1 \star}$ Yuan Han, ${ }^{1,2,3 \star}$ Yue-Peng Liu, ${ }^{2,3 *}$ Angela A. Song, ${ }^{1}$ Beth Barnes, ${ }^{1}$ and Xue-Jun Song ${ }^{1,2,3}$ \\ ${ }^{1}$ Department of Neurobiology, Parker University Research Institute, Dallas, Texas 75229, and ${ }^{2}$ Jiangsu Province Key Laboratory of Anesthesiology and \\ ${ }^{3}$ Center for Pain Research and Treatment, Xuzhou Medical College, Xuzhou, Jiangsu 221002, China
}

Preventing and reversing opioid dependence continues to be a clinical challenge and underlying mechanisms of opioid actions remain elusive. We report that matrix metalloproteinase-9 (MMP-9) in the spinal cord contributes to development of physical dependence on morphine. Chronic morphine exposure and naloxone-precipitated withdrawal increase activity of spinal MMP-9. Spinal inhibition or targeted mutation of MMP-9 suppresses behavioral signs of morphine withdrawal and the associated neurochemical alterations. The increased MMP-9 activity is mainly distributed in the superficial dorsal horn and colocalized primarily with neurons and small numbers of astrocytes and microglia. Morphine exposure and withdrawal increase phosphorylation of NR1 and NR2B receptors, ERK1/2, calmodulin-dependent kinase II, and cAMP response element binding proteins; and such phosphorylation is suppressed by either spinal inhibition or targeted mutation of MMP-9. Further, spinal administration of exogenous MMP-9 induces morphine withdrawal-like behavioral signs and mechanical allodynia, activates NR1 and NR2 receptors, and downregulates integrin- $\beta 1$, while a function-neutralizing antibody against integrin- $\beta 1$ suppresses MMP-9-induced phosphorylation of NR1 and NR2B. Morphine withdrawal-induced MMP-9 activity is also reduced by an nNOS inhibitor. Thus, we hypothesize that spinal MMP-9 may contribute to the development of morphine dependence primarily through neuronal activation and interaction with NR1 and NR2B receptors via integrin- $\beta 1$ and NO pathways. The other gelatinase, MMP-2, is not involved in morphine dependence. Inhibiting spinal MMP-9 or MMP-2 reduces chronic and/or acute morphine tolerance. This study suggests a novel therapeutic approach for preventing, minimizing, or reversing opioid dependence and tolerance.

\section{Introduction}

Opioid drugs have been used and abused for their analgesic and rewarding properties. Mechanisms of opiate dependence and tolerance are complex and involve factors at levels of the drug receptor, the cell, and neural networks. Roles of diverse neurotransmitter and receptor systems and intracellular signaling proteins in opioid actions have been demonstrated. A glutamate/ NMDA receptor (NMDAR)/NO cascade is the most intensively studied system (Kolesnikov et al., 1993; Inoue et al., 2003; Zachariou et al., 2003; Bailey and Connor, 2005; Pasternak and Kolesnikov, 2005; Muscoli et al., 2007; Pasternak, 2007; Liu et al., 2009a). Adaptive changes following chronic opioid exposure that might underlie physical dependence by altering neuronal excitability and synaptic transmission include a rebound increase in cAMP levels and in expression of certain types of adenylyl cyclase,

\footnotetext{
Received March 16, 2010; revised April 14, 2010; accepted April 22, 2010.

This project was supported by grants from the Parker Research Foundation (PCCRF-BSR0804/0905), National Natural Science Foundation of China (NSFC-30628027), and National Institutes of Health of the United States (NIH1R43AT004933-01). We thank Dr. E.T. Walters for his comment and editing the manuscript, Dr. Z.J. Huang for technical assistance in data analysis, Dr. R.L. Rupert for advice and stimulating discussion, Dr. P. Brandon for proofreading, and M. Dominguez, Y.-P. Wu, and P.C. Xu for technical support and assistance in laboratory management. W.-T.L., Y.H., Y.-P.L., A.A.S., and B.B. designed and performed the experiments; X.-J.S. conceived the study, designed and supervised the overall project and the experiments, analyzed data, and wrote the manuscript. This work should be attributed equally to the institutions.

${ }^{*}$ W. -T.L., Y.H., and Y.-P.L. contributed equally to this work.

Correspondence should be addressed to Xue-Jun Song, Department of Neurobiology, Parker University Research Institute, 2500 Walnut Hill Lane, Dallas, TX 75229. E-mail: song@parkercc.edu.

DOI:10.1523/JNEUROSCI.1358-10.2010

Copyright $\odot 2010$ the authors $\quad 0270-6474 / 10 / 307613-11 \$ 15.00 / 0$
}

guanylyl cyclase, PKA, PKG, and cAMP response element binding protein (CREB) (Nestler, 2001; Barrot et al., 2002; ShawLutchman et al., 2002). The regions important in opioid actions include the spinal cord and supraspinal levels (Jhamandas et al., 1996; Bailey and Connor, 2005; Muscoli et al., 2007; Han et al., 2008; Liu et al., 2009a). Despite decades of investigation, the specific cellular and molecular mechanisms underlying opioid actions remain elusive. Opiate tolerance and dependence and many side effects during repeated use have limited opioid use in the clinic. Thus, preventing and reversing opioid dependence and tolerance is still a clinical challenge.

Matrix metalloproteinases (MMPs), which belong to the metzincin clan of the metalloproteinase superfamily and are expressed in both neurons and glia, are widely implicated in inflammation and tissue remodeling through the cleavage of extracellular matrix (ECM) proteins, cytokines, and chemokines. Studies have shown that MMPs can regulate diverse biological processes including inflammation and responses to injury of peripheral nerve, spinal cord, and brain (Wang et al., 2000; Yong et al., 2001; Overall and López-Otín, 2002; Parks et al., 2004; Yong, 2005; Zhao et al., 2006; Chattopadhyay et al., 2007; Ethell and Ethell, 2007). In particular, the two gelatinases, MMP-9 and MMP-2, distinguished by three cysteine-rich fibronectin type II repeats in the catalytic domain, have recently been shown to play important roles in neuropathic pain (Kawasaki et al., 2008). We hypothesized that MMP-9 and/or MMP-2 might play an important role in chronic opioid action. We here provide the first evidence that spinal MMP-9, but not MMP-2, plays a critical role in development 

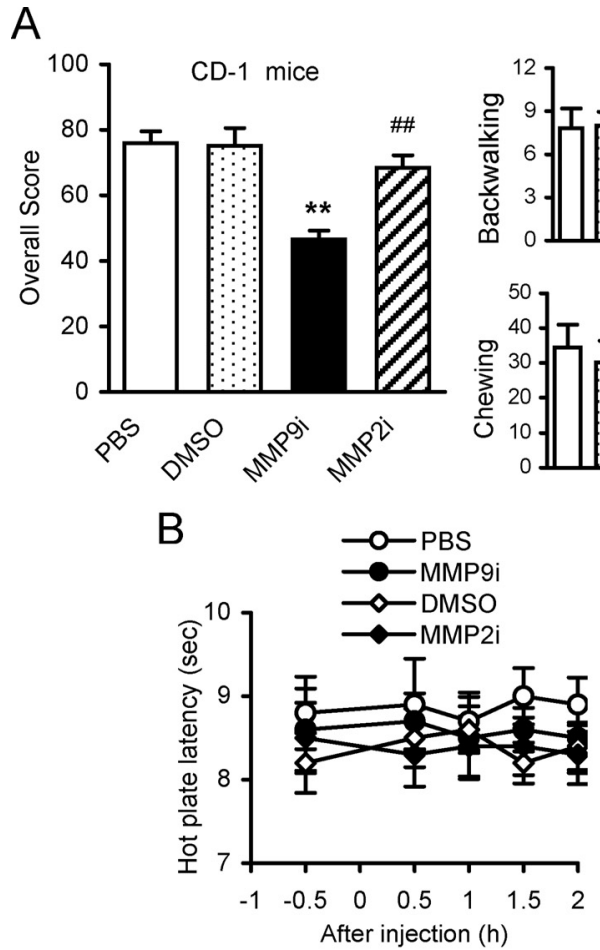
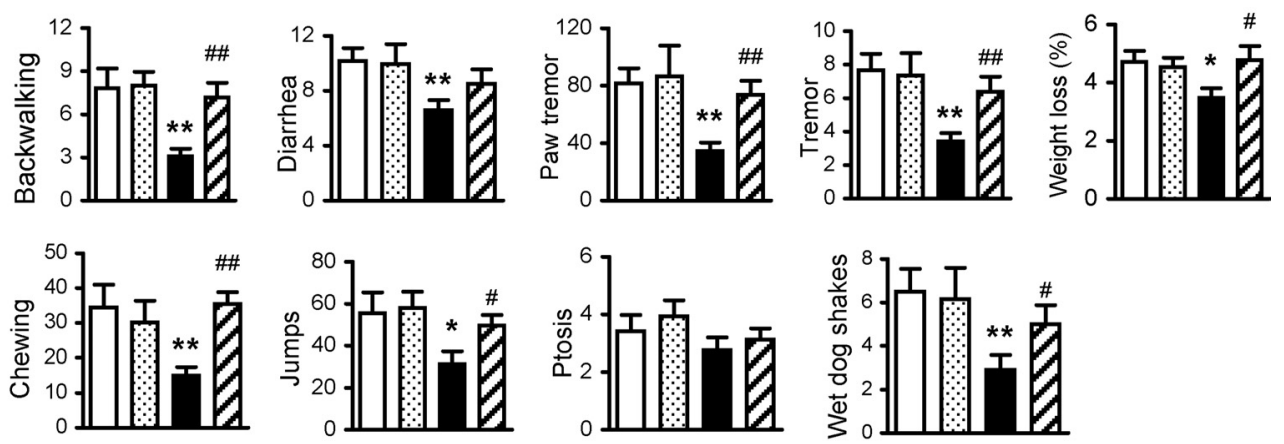

C

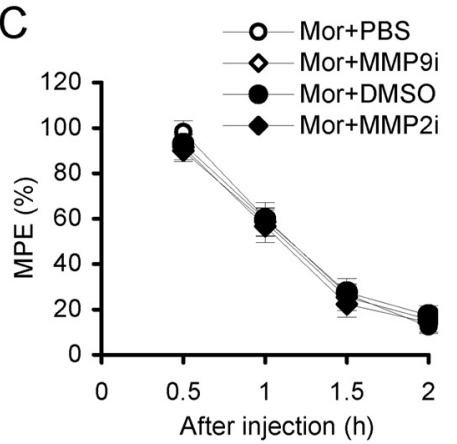

D

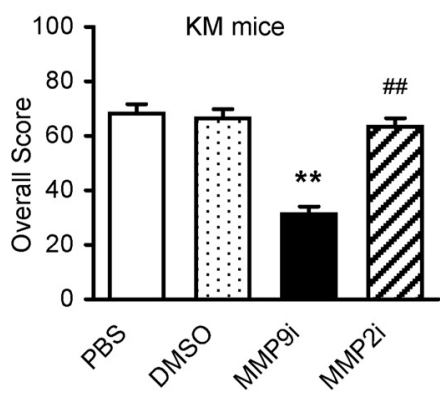

Figure 1. Inhibition of spinal MMP-9, but not MMP-2, attenuates behavioral signs of naloxone-precipitated morphine withdrawal. $\boldsymbol{A}$, Effects of MMP-9 inhibitor MMP9i and MMP-2 inhibitor MMP2i on behavioral signs. In addition to receiving morphine (intraperitoneally) and naloxone (subcutaneously), the different groups received one of the following treatments (intrathecally): PBS and DMSO (1\%) for vehicle controls, MMP9i, and MMP2i (5 $\mu$ g each, 7 doses accompanied morphine). ${ }^{*} p<0.05$ and ${ }^{* *} p<0.01$ compared to vehicle control. ${ }^{\#} p<0.05$ and ${ }^{\# \#} p<0.01$ compared to group of MMP9i. Number of mice in each group: $\mathrm{PBS}=12, \mathrm{DMSO}=14, \mathrm{MMP} \mathrm{i}=12, \mathrm{MMP} 2 \mathrm{i}=16 . \boldsymbol{B}$, Effects of MMP9i and MMP2i (intrathecal) on the pain threshold in naive mice ( $n=14$ each group). $\boldsymbol{C}$, Effects of MMP9i and MMP2i (intrathecal) on the initial analgesic response to morphine (Mor, intraperitoneal) ( $n=14$ each group). PBS and DMSO were used as intrathecal controls in $\boldsymbol{B}$ and $\mathbf{C}$. $\boldsymbol{D}$, Effects of MMP9i and MMP2i on behavioral signs of morphine withdrawal in another strain of animals, KM mice. Sixteen mice were included in each group. ${ }^{* *} p<0.01$ compared to vehicle controls; ${ }^{\# \#} p<0.01$ compared to group of MMP9i.

of morphine dependence. Mechanistically, MMP-9 may act primarily through neuronal activation and interact with NMDAR subunits NR1 and NR2B via integrin- $\beta 1$ and NO pathways.

\section{Materials and Methods}

Experimental animals. Adult male and female CD-1 mice (Charles River Laboratories) and MMP-9 mutant $\left(\mathrm{Mmp}^{9^{-1-}}\right)$ and wild-type (WT) FVB mice (The Jackson Laboratory) weighing $24-28 \mathrm{~g}$ at $8-10$ weeks of age were used. Female mice were used for the pain threshold and morphine analgesia/tolerance tests using the hot plate apparatus because pain was predicted to be evoked by contact of the testicle with the hot plate; male mice were used for all other experiments. A cutoff time of $30 \mathrm{~s}$ was set to avoid tissue damage. As described by The Jackson Laboratory, a targeting vector containing a neomycin resistance gene driven by the mouse phosphoglycerate kinase promoter was used to disrupt most of exon 1 and all of intron 2 of the MMP-9 gene. The construct was electroporated into 129S-derived ZW4 embryonic stem cells. Correctly targeted embryonic stem cells were injected into C57BL/6J blastocysts. The resulting chimeric male animals were mated with Black Swiss females. Progeny animals were mated to Black Swiss mice for an unknown number of generations before being mated with FVB animals. The mice were maintained in FVB background for more than five generations. The experimental protocol was approved by the Parker Research Institutional Animal Care and Use Committee. Adult Kunming (KM) mice were also used to confirm the behavioral studies in different mouse strains (Fig. $1 D)$. KM mice were provided by the Experimental Animal Center at Xuzhou Medical College (XMC). The experiments in KM mice were performed in the Jiangsu Province Key Laboratory of Anesthesiology at XMC.

Animal anesthesia, drugs, and administration. Mice were anesthetized with pentobarbital (50 mg/kg, i.p.) for preparing the spinal cord tissue for gelatin zymography, Western blotting, and immunobiochemistry. We purchased MMP-9 inhibitor Inhibitor-I (MMP9i), MMP-2 inhibitor Inhibitor-III (MMP2i), and MMP-9 from Calbiochem; an nNOS inhib- itor, 7-nitroindazole (7NI), morphine, and naloxone from SigmaAldrich; and a function-neutralizing integrin- $\beta 1$ antibody ( $\beta 1 \mathrm{ab})$ from Millipore. Each of these drugs was dissolved in PBS or DMSO and diluted in PBS (final concentration of DMSO for intrathecal administration was 1\%). MMP-9 (0.4 pmol), MMP9i (5 $\mu \mathrm{g})$, MMP2i (5 $\mu \mathrm{g}), 7 \mathrm{NI}(50 \mathrm{nmol})$, and $\beta 1 \mathrm{ab}(2 \mu \mathrm{g})$ and the vehicle controls PBS and DMSO were injected intrathecally (each in $10 \mu \mathrm{l}$ ), respectively, under brief inhalational anesthesia or $\sim 5 \mathrm{~min}$ after each morphine injection, by means of lumbar puncture at the intervertebral space of L4-5 and L5-6 for multiple injections, using a stainless steel needle (30 gauge) attached to a $25 \mu \mathrm{l}$ Hamilton syringe.

Morphine withdrawal. Mice were repeatedly injected with morphine in seven escalating doses every $8 \mathrm{~h}(20,40,60,80,100,100$, and $100 \mathrm{mg} / \mathrm{kg}$, i.p.). Two hours after the last morphine injection, mice were injected with naloxone ( $1 \mathrm{mg} / \mathrm{kg}$, s.c.), and withdrawal symptoms were monitored for $30 \mathrm{~min}$ after naloxone administration. For testing the morphine withdrawal-like behavioral signs following intrathecal MMP-9, the withdrawal symptoms were monitored for $30 \mathrm{~min} 2 \mathrm{~h}$ after naloxone administration. In addition to measuring individual withdrawal signs, an overall opiate withdrawal score was calculated as (no. of backward walking steps $\times 0.1)+($ diarrhea $\times 2)+($ no. of jumps $\times 0.1)+($ paw tremor $\times 0.1)+$ ptosis + tremor $+(\%$ weight loss $\times 5)+$ no. of wet-dog shakes (Zachariou et al., 2003; Liu et al., 2009a).

Pain threshold and morphine analgesia tests. To test effects of MMP-9 and MMP-2 inhibitors on the pain threshold and the initial analgesic response to morphine, mice were placed on a $55^{\circ} \mathrm{C}$ hot plate apparatus, and the latency to lick a paw was measured. Data were calculated as percentage maximal possible effect (MPE\%), which was calculated by the following formula: $100 \times[($ drug response time - basal response time $) /$ $(30 \mathrm{~s}-$ basal response time $)]=$ MPE\%. Morphine $(10 \mathrm{mg} / \mathrm{kg}$, s.c.), MMP9i (5 $\mu$ g, i.t.), MMP2i (5 $\mu$ g, i.t.), and the control vehicles PBS and $\operatorname{DMSO}(1 \%$, i.t.) were administered $30 \mathrm{~min}$ before testing. The protocol 
was the same as that previously described (Zachariou et al., 2003; Liu et al., 2009a).

Mechanical allodynia test. Mechanical allodynia was indicated by a significant decrease in the threshold of paw withdrawal in response to mechanical indentation of the plantar surface of each hindpaw with a sharp, cylindrical probe with a uniform tip diameter of $\sim 0.2 \mathrm{~mm}$ provided by an Electrovonfrey (Almemo 2390-5, Anesthesiometer IITC). The probe was applied to four designated loci distributed over the plantar surface of the hindpaw. The minimal force (in grams) that induced paw withdrawal was read off the display. Threshold of mechanical withdrawal in each mouse was calculated by averaging the four readings, and the force was converted into millinewtons.

Morphine tolerance tests. To evaluate the physical tolerance to morphine, a profound decrease in analgesic effect, each female mouse was placed on a $55^{\circ} \mathrm{C}$ hot plate apparatus, and the latency to lick a paw was measured following subcutaneous morphine injection. For testing acute tolerance, the latency to lick a paw was measured at $0.5,1,1.5$, and $2 \mathrm{~h}$ after a single dose of morphine at $10 \mathrm{mg} / \mathrm{kg}$, administered $24 \mathrm{~h}$ after a morphine treatment at $100 \mathrm{mg} / \mathrm{kg}$ (protocol abbreviated as Mor 100-10). To mimic clinical long-term use of morphine at high doses, we further tested morphine tolerance using a model measuring the analgesic effect of a single dose of morphine at $10 \mathrm{mg} / \mathrm{kg}$ each day followed by repetitive morphine at $50 \mathrm{mg} / \mathrm{kg} 2 \mathrm{~h}$ afterward, for 7 consecutive days (protocol abbreviated as Mor10-50). Chronic tolerance was also tested following repetitive treatment of morphine at $10 \mathrm{mg} / \mathrm{kg}$ given daily for $7 \mathrm{~d}$, and the analgesic effect was measured $30 \mathrm{~min}$ after each injection (protocol abbreviated as Mor10).

Gelatin zymography. The protocol was similar to that previously described (Gasche et al., 1999; Kawasaki et al., 2008). The animals were anesthetized deeply and transcardially perfused with PBS, and then a length of spinal cord containing segments L1-L6 was rapidly dissected and homogenized in a lysis buffer containing proteinase inhibitors. Aliquots $(10 \mu \mathrm{l})$ of the homogenates were saved for total protein measurement (BCA kit). The homogenates were centrifuged at 12,000 RPM for 5 $\mathrm{min}$. The supernatants were recovered and incubated for $60 \mathrm{~min}$ with gelatin-Sepharose 4B (Pharmacia Biotech) with constant shaking. After incubation, the samples were centrifuged at 500 RPM for $2 \mathrm{~min}$. The pellets were resuspended in $80 \mu \mathrm{l}$ of elution buffer for $30 \mathrm{~min}$. The entire sample was loaded onto a $8 \%$ SDS gel containing $1 \mathrm{mg} / \mathrm{ml}$ gelatin. The gel was washed for 3-4 h to remove SDS and allow renaturation of MMPs. The gel was then left for $48 \mathrm{~h}$ in an incubation buffer to allow MMPs to degrade the gelatin in their immediate vicinity. Finally, zones of gelatin degradation representing proteolytic activity were identified by staining the gel with Coomassie Blue and destaining with methanol and acetic acid in water $(3: 1: 6)$.

Western blotting. To identify temporal expression of the phosphorylated protein levels of NR1, NR2B, ERK, calmodulin-dependent kinase II (CaMKII), CREB, glial fibrillary acidic protein (GFAP), and GAPDH, whole-cell protein extract lysates were used. The protocol was similar to that described previously (Bundesen et al., 2003; Liu et al., 2009a). Under anesthesia and immediately after perfusion with PBS, the mice spinal cord tissue at segments L1-L6 was rapidly removed and homogenized. After transfer to nitrocellulose filters, the filters were blocked with $5 \%$ bovine serum albumin (BSA) and then incubated overnight at $4^{\circ} \mathrm{C}$ with the primary antibodies [pNR1 (Ser897), 1:800 from Millipore; pNR2B (Tyr1472), 1:300 from Millipore Bioscience Research Reagents; pERK1/2 (Thr202/Tyr204), 1:500, and pCaMKII (Thr286), 1:1000 from Cell Signaling Technology; GAPDH, 1:1000 from Sigma; GFAP and pCREB (Ser133) from Santa Cruz Biotechnology] and anti-integrin $\beta 1$ (MAB1987Z, 1:500, Millipore). The filters were developed using ECL reagents (PerkinElmer) with secondary antibodies from Millipore Bioscience Research Reagents. Data were analyzed with a Molecular Imager (Gel DocTM XR, 170-8170) and the associated software Quantity One4.6.5 (Bio-Rad Laboratories).

Immunohistochemistry. Under deep anesthesia, mice were transcardially perfused with PBS followed by $4 \%$ paraformaldehyde with $1.5 \%$ picric acid in $0.16 \mathrm{M} \mathrm{PB}\left(\mathrm{pH} 7.2-7.4,4^{\circ} \mathrm{C}\right)$, and then the $\mathrm{L} 4$ and/or L5 lumbar segment was dissected out and postfixed in the same fixative overnight. The embedded blocks were sectioned (30 $\mu \mathrm{m}$ thick) and pro- cessed for immunofluorescence. Sections from each group (five mice in each group) were incubated with rabbit anti-c-Fos polyclonal antibody (1:100, sc-52, Santa Cruz Biotechnology), rabbit anti-calcitonin generelated peptide (CGRP) polyclonal antibody (1:1000, Millipore), goat anti-MMP-9 (1:500, M9570, Sigma) and rabbit anti-MMP-9 (1:500, AB19016, Millipore) polyclonal antibodies, mouse monoclonal antineuronal nuclear protein (NeuN) for identifying neurons (1:100, Alexa Fluor-488 conjugated, MAB377X, Millipore Bioscience Research Reagents), rabbit polyclonal anti-GFAP (1:500, ab7260, Abcam), and rabbit polyclonal anti-IBA (1:100, 019-19741, Wako Pure Chemical Industries), respectively. Rabbit IgG (1:200, Vector Laboratories) was used as an isotype control. For double immunofluorescence staining, the freefloating sections were incubated in PBS containing 10\% donkey serum and $1 \% \mathrm{BSA}$ for $2 \mathrm{~h}$, incubated at $4^{\circ} \mathrm{C}$ in primary antibody, then washed three times in $50 \mathrm{~mm}$ Tris- $\mathrm{HCl}(\mathrm{pH}=7.4) \mathrm{PBS}$, and incubated in the secondary antibody either for $2 \mathrm{~h}$ at room temperature or overnight at $4^{\circ} \mathrm{C}$. After washing three times in PBS, sections were reincubated in blocking serum for $1 \mathrm{~h}$. Morphologic details examined with a confocal microscope (Leica TCS SP2). Images were randomly coded and transferred to a computer for further analysis. Fos-immunoreactive neurons were counted in a blind fashion. The number of Fos-like-immunoreactive neurons in the dorsal horn $(\mathrm{DH})$ of the spinal cord (laminae I-VII) was determined by averaging the counts made in 20 spinal cord sections for each group. To obtain quantitative measurements of CGRP immunofluorescence, 15-20 fields covering the entire DH in each group were evaluated and photographed at the same exposure time to generate the raw data. Fluorescence intensities of the different groups were analyzed using MicroSuite image analysis software (Olympus America). The average green fluorescence intensity of each pixel was normalized to the background intensity in the same image.

Statistics. SPSS Rel 15 was used to conduct all the statistical analyses. Alteration of expression of the proteins detected and the behavioral responses to morphine withdrawal were tested with one-way ANOVA and the differences in latency over time among groups were tested with twoway ANOVA with repeated measures, respectively, followed by Bonferroni post hoc tests. All data are presented as mean \pm SEM. Statistical results are considered significant if $p<0.05$.

\section{Results}

Inhibition of spinal MMP-9, but not MMP-2, or targeted mutation of MMP-9 suppresses behavioral and neurochemical signs of naloxone-precipitated morphine withdrawal

Spinal coadministration of an MMP-9 inhibitor, MMP9i (5 $\mu \mathrm{g} / 10 \mu \mathrm{l}$, i.t.), but not an MMP-2 inhibitor, MMP2i (5 $\mu \mathrm{g} / 10 \mu \mathrm{l}$, i.t.), with morphine (i.p., seven escalating doses every $8 \mathrm{~h}$ ) significantly attenuated behavioral signs of morphine withdrawal in CD-1 mice. The overall score and individual behavioral signs were reduced significantly compared with the control groups (Fig. 1 A). Neither MMP9i nor MMP2i altered the pain threshold (Fig. $1 B$ ) or the initial morphine-induced analgesia (Fig. 1C) in naive mice. Similar effects were observed in another mouse strain, the KM mice (Fig. 1D). These pharmacological data were further confirmed in mice lacking MMP-9 $\left(\mathrm{Mmp9}^{-1-}\right)$. The overall score significantly decreased and the individual behavioral signs observed were significantly suppressed in Mmp9-/mice compared with those in WT FVB mice with the same genetic background (Fig. 2). We noticed that WT FVB mice exhibited significantly lower overall scores and individual signs than did WT CD-1 (Fig. 1A) or WT KM mice (Fig. 1D) (overall scores: $\mathrm{CD}-1$ vs $\mathrm{KM}=76.0 \pm 3.54 \%$ vs $68.2 \pm 3.36 \%, p>0.05 ; \mathrm{CD}-1$ vs $\operatorname{FVB}(48.6 \pm 1.98 \%), p<0.01 ; \mathrm{KM}$ vs FVB, $p<0.01)$. We further tested pharmacological effects on WT FVB and the $M m p 9^{-1-}$ mice. MMP9i significantly attenuated behavioral signs of morphine withdrawal in WT FVB mice, but did not produce further inhibition in Mmp9-/- mice (Fig. 2). These results demonstrate 

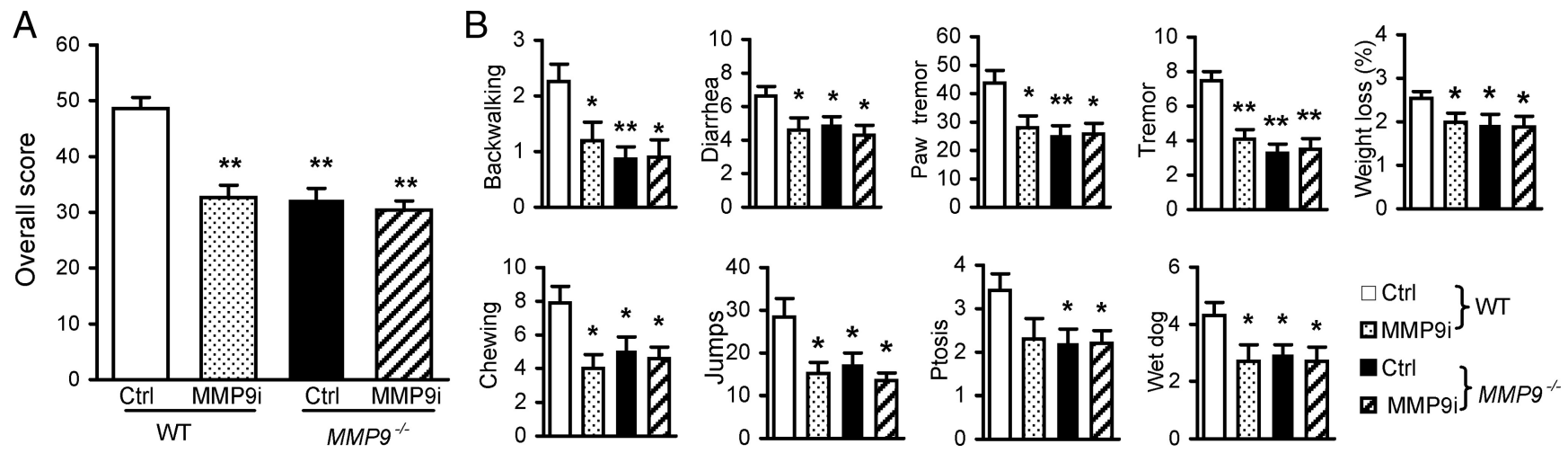

Figure 2. Spinal inhibition and targeted mutation of MMP-9 attenuate behavioral signs of naloxone-precipitated morphine withdrawal. $\boldsymbol{A}, \boldsymbol{B}, 0$ verall withdrawal scores $(\boldsymbol{A})$ were calculated from the individual signs $(\boldsymbol{B}) .^{*} p<0.05,{ }^{* *} p<0.01$ compared to the control (Ctrl) group in WT or MMP-9 mutation (Mmp $9^{-1-}$ ) group. Number of mice in each group: WT Ctrl $=20$, WT MMP9i $=10$, Mmp9-/-Ctrl $=15$, Mmp9 $^{-/-} \mathrm{MMP} 9 \mathrm{i}=10$.

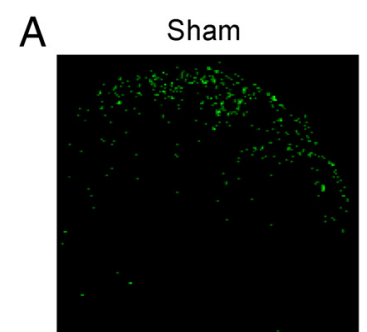

Mor+Nlx

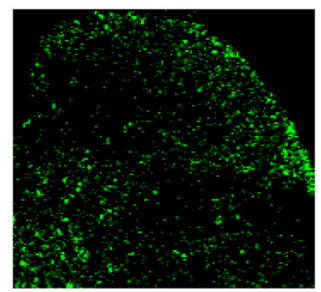

Mor+MMP2I+NIx

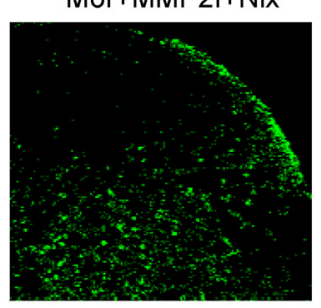

Mor

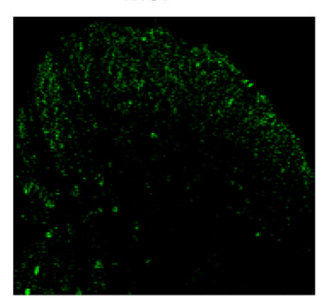

Mor+MMP9|+NIx
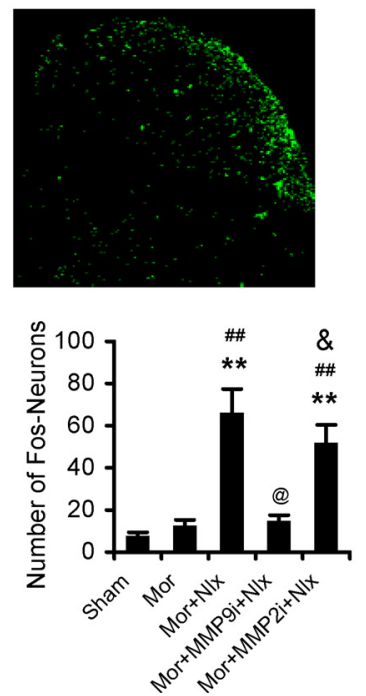

B

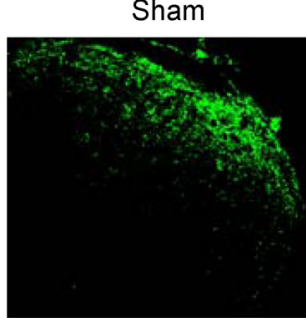

Mor+MMP2i

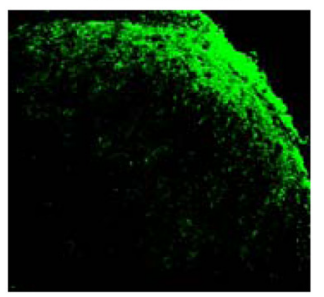

Mor+MMP2i+Nlx

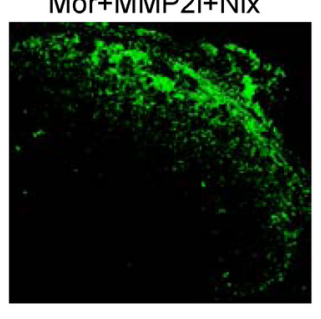

Mor

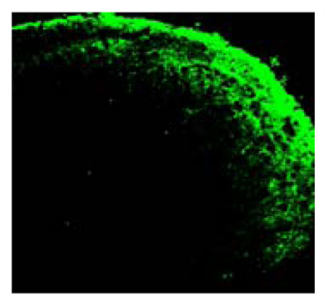

Mor+Nlx
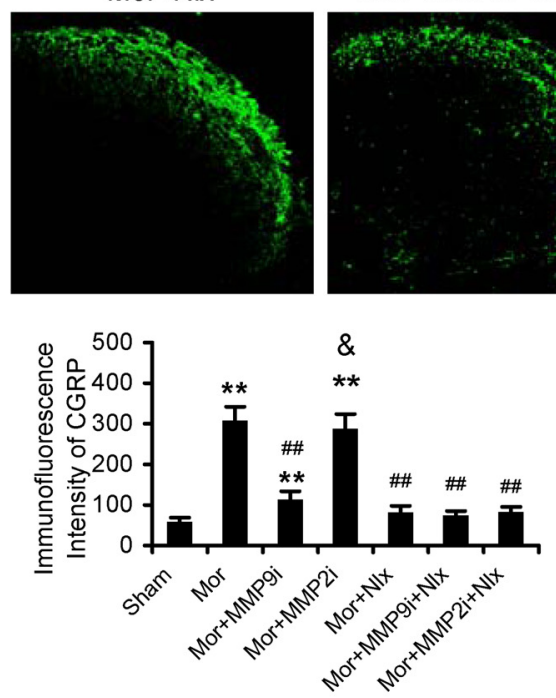

Mor+MMP9i

Mor+MMP9i+NIx
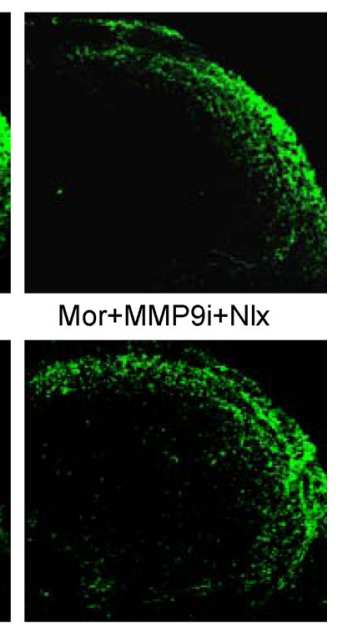

Figure 3. Effects of MMP-9 inhibitor MMP9i and MMP-2 inhibitor MMP2i on induction of c-Fos and expression of CGRP in the DH following morphine (Mor) treatment and/or naloxone (NIx)-precipitated withdrawal. $A$, MMP9i, but not MMP2i, inhibits induction of c-Fos in the DH following Nlx-precipitated withdrawal. Confocal image shows examples of induction of c-Fos in the DH. Bottom, Data summary. B, MMP9i, but not MMP2i, prevents accumulation of CGRP in the superficial DH following Mor treatment. Confocal image shows examples of expression of CGRP in the DH. Bottom, Data summary. Five spinal cord segments were included in each group. ${ }^{* *} p<0.01$ compared to group of sham; ${ }^{\# \#} p<0.01$ compared to group of Mor; ${ }^{@} p<0.05$ compared to group of $($ Mor + NIx $) ;{ }^{\&} p<0.05$ compared to group of Mor + MMP9i $+\mathrm{Nlx}(\boldsymbol{A})$ or Mor + MMP9i $(\boldsymbol{B})$. Magnification: $200 \times$.

an important role of spinal MMP-9, but not MMP-2, in the development of morphine physical dependence.

In addition to the behavioral signs, morphine exposure and withdrawal caused significant neurochemical alterations, induction of c-Fos (Fig. 3A), increased CGRP-like immunoreactivity (Fig. 3B), and spinal astrocyte activation (Fig. 4) manifested as upregulation of expression of GFAP (an astrocyte marker) and increases in both astrocyte number and size in the $\mathrm{DH}$. Repetitive administration of MMP9i, but not MMP2i, prevented or suppressed these neurochemical changes.
Activity and distribution of spinal MMP-9 and MMP-2 following morphine exposure and withdrawal

Given that blocking spinal activity of MMP-9, but not MMP-2, or targeted mutation of MMP-9 can prevent development of behavioral and neurochemical signs associated with morphine exposure and withdrawal, we examined the activity of MMP-9 and MMP-2 using gelatin zymography in the spinal cord under the same conditions. MMP-9 activity was significantly increased following morphine exposure and further increased after morphine withdrawal. Activity peaked $30 \mathrm{~min}$ after withdrawal, whereas 
A
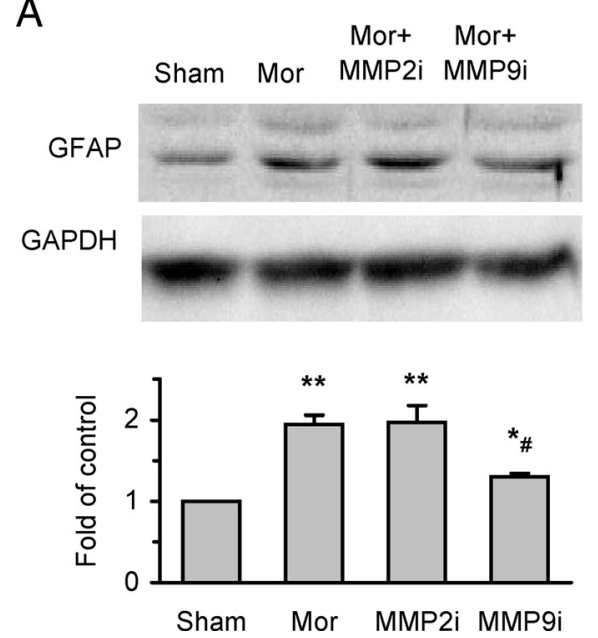

B
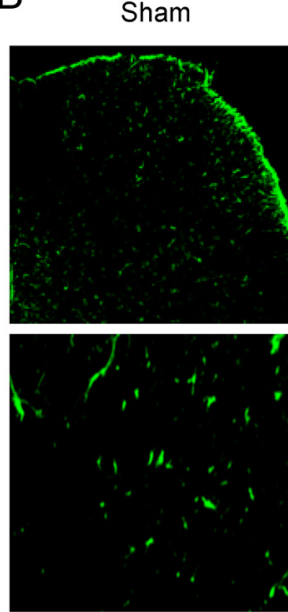

Mor
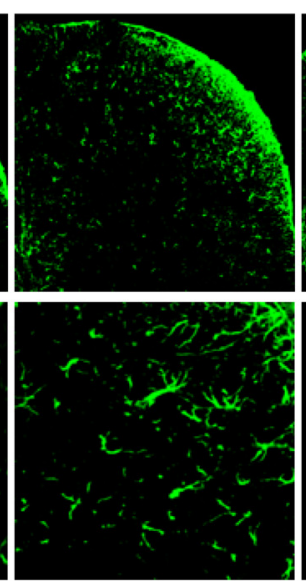

Mor+MMP9i

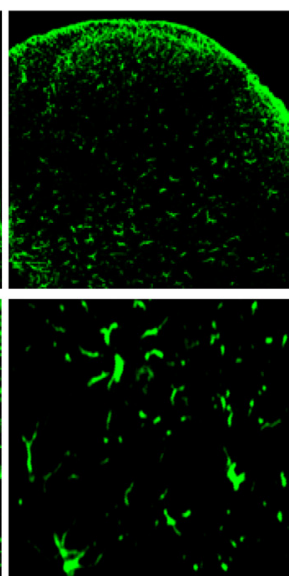

Figure 4. MMP-9 inhibitor MMP9i, but not MMP-2 inhibitor MMP2i, suppresses morphine (Mor) exposure-induced activation of astrocytes in the spinal cord. $\boldsymbol{A}$, Western blot analysis shows expression of GFAP (a marker for astrocytes) (top: examples; bottom: data summary). ${ }^{*} p<0.05$ compared to group of sham; ${ }^{* *} p<0.01$ compared to group of sham; ${ }^{\#} p<0.05$ compared to group of Mor and MMP2i. Four spinal cord segments were included in each group. $\boldsymbol{B}$, Examples of confocal images showing GFAP activation in the DH. Magnification: $200 \times$ (top), $400 \times$ (bottom).

A
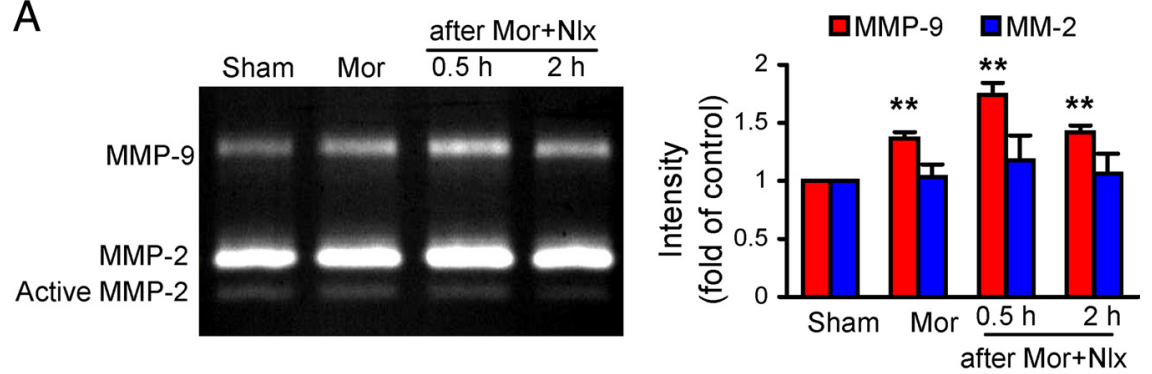

B

Naive
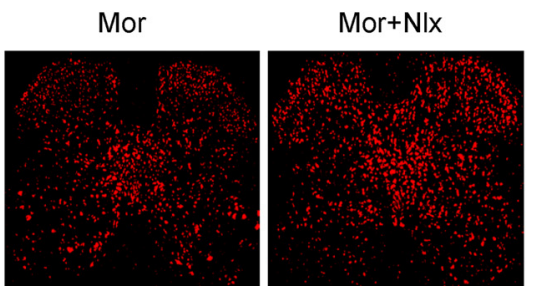

Figure 5. Upregulation of MMP-9, but not MMP-2, in the spinal cord following morphine (Mor) exposure and naloxone (NIx)precipitated withdrawal. $A$, Gelatin zymography shows activity of MMP-9 and MMP-2 (Pro-MMP-2 and active MMP-2). Intensity of MMP-9 and pro-MMP- 2 bands, expressed as multiples of values in the sham control, is shown on the right. ${ }^{* *} p<0.01$ compared to sham. Six segments of the spinal cord were used in each group for MMP-9 and MMP-2, respectively. $\boldsymbol{B}$, Confocal image of immunostaining for MMP-9 showing increased activity of MMP-9 in the DH. Magnification: $100 \times$.

MMP-2 (pro- and active) activity was not changed (Fig. 5A). The increased immunostaining for MMP-9 was located mainly in the superficial layers and inner parts of laminae III-VI of the DH (Fig. 5B).

We further asked (1) with which neurons, astrocytes, and/or microglia within the DH MMP-9 immunoreactivity was colocalized; (2) whether the MMP-9 was associated with IB4-positive nociceptor terminals; and c) whether the MMP-9 colocalized with CGRP afferents following morphine treatment. Confocal images showed that, in naive mice, the MMP-9 immunoreactivity was distributed throughout the $\mathrm{DH}$ and ventral horn and colocalized primarily with neurons (as indicated by NeuN, a neuronal marker) (Fig. 6A, top). The increased MMP-9 immunoreactivity after morphine exposure (Fig. 6A, middle) and naloxone-precipitated morphine withdrawal (Fig. 6A, bottom) was mainly distributed in the superficial layers and inner parts of laminae III-VI of the DH and colocalized primarily with neurons, while only a small amount of colocalization of
MMP-9 with astrocytes (GFAP) (Fig. 6B, left two panels) and microglia (IBA, a microglia marker) (Fig. $6 B$, right two panels). However, our results failed to show any colocalization of MMP-9 immunoreactivity with either IB4-positive terminals (Fig. 6C, left two panels) or CGRP-positive nociceptive primary afferents (Fig. $6 C$, right two panels). These results indicate that morphine treatment primarily upregulates neuronal MMP-9 within the $\mathrm{DH}$.

Inhibition of spinal MMP-9 or targeted mutation of MMP-9 suppresses upregulation of phosphorylation of NR1, NR2B, ERK, CaMKII, and CREB associated with morphine exposure and withdrawal

NMDARs have a well established role in opiate-related neural plasticity. Chronic morphine treatment causes increases in $\mathrm{Ca}^{2+}$ levels and alterations of ERK (Ren et al., 2004), CaMKII (Lu et al., 2000; Liang et al., 2004), and CREB (Nestler, 2001). Our Western blotting analysis showed that morphine exposure and withdrawal-induced increases of levels of phosphorylation of NR1, NR2B, ERK1/2, CaMKII, and CREB protein were significantly reduced by MMP-9 inhibitor MMP9i ( $5 \mu$ g, i.t.) (Fig. $7 A, B$ ). These findings indicate that MMP-9 may contribute to morphine dependence, probably via interaction with NR1 and NR2B receptors and activation of subsequent signaling pathways. These alterations were further confirmed in Mmp9-/- mice; morphine withdrawal-induced phosphorylation of NR1 and NR2B was significantly less in $\mathrm{Mmp}^{-1-}$ mice than in WT FVB mice (Fig. 7C).

\section{Spinal administration of exogenous MMP-9 induces} morphine withdrawal-like behavioral signs and increases levels of phosphorylation of NR1, NR2B, and CREB

To determine whether exogenous MMP-9 is sufficient to mimic the morphine withdrawal-like behavioral signs and the morphine treatment-activated and MMP-9-regulated NMDARs and subse- 
A
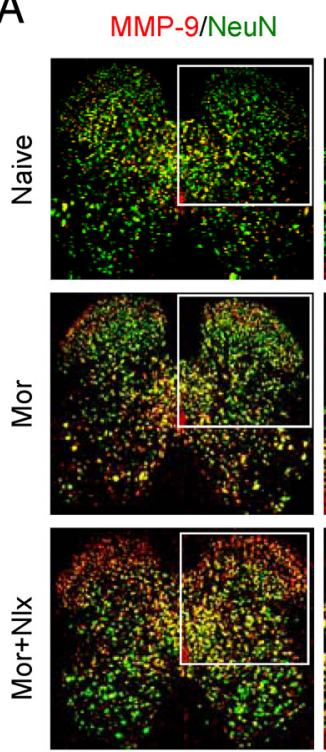

MMP-9/NeuN
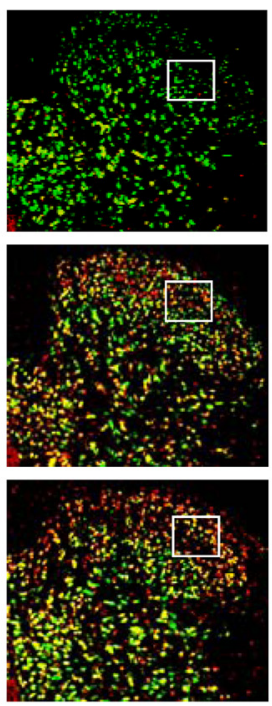

C

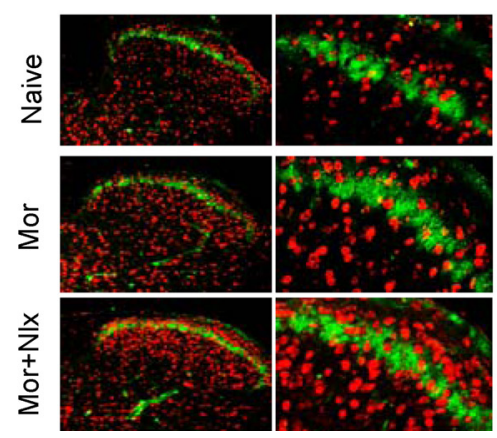

MMP-9/NeuN
B
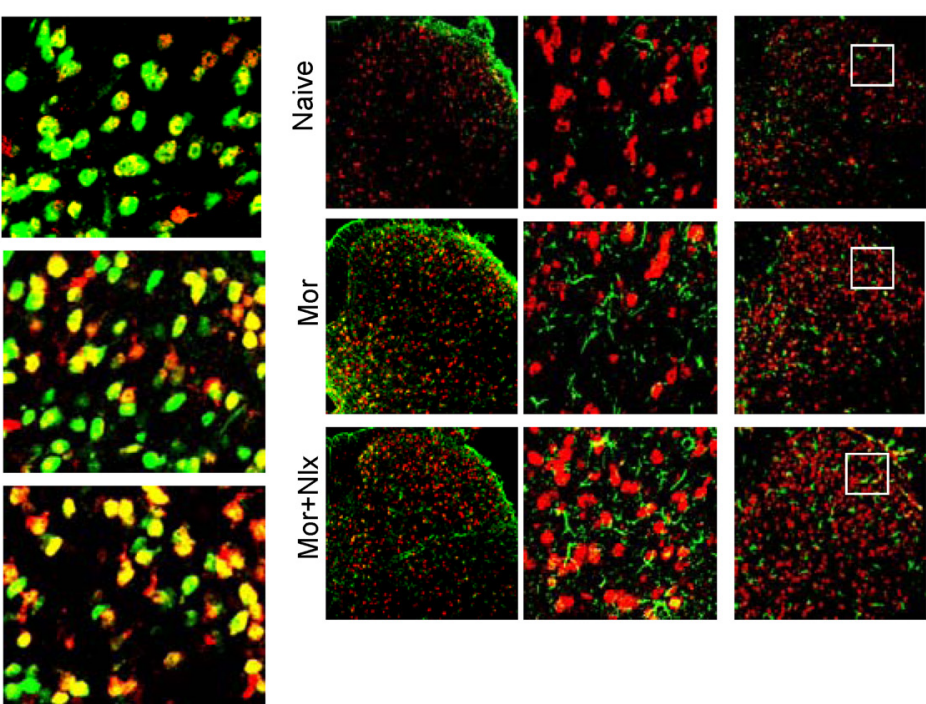

MMP-9/IBA
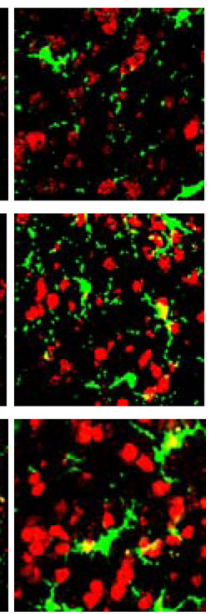

MMP-9/CGRP

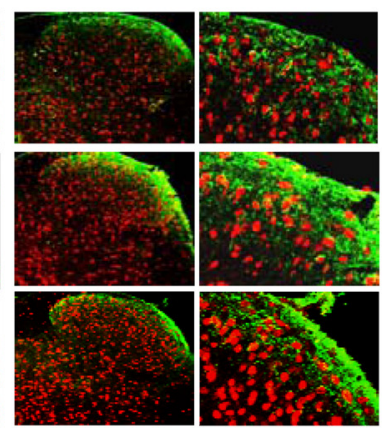

Figure 6. Distribution and colocalization of MMP-9 with neurons, astrocytes, and microglial cells, but not the primary afferents in the dorsal horn after morphine (Mor) exposure and naloxone (NIx)-precipitated withdrawal. $A$, Distribution of MMP-9 (red) and its colocalization with the neurons (NeuN, green, a marker of neurons). Magnification: $100 \times($ left); $200 \times($ middle); $400 \times$ (right). $B$, A small amount of colocalization of MMP-9 (red) with astrocytes (GFAP, green, left two panels) or microglia (IBA, green, right two panels). C, MMP-9 (red) was not colocalized with IB4 (green, left two panels) or (GRP (green, right two panels) primary afferents. Magnification in $B$ and $C: 200 \times$ (the first and the third panels); $400 \times$ (the second and the fourth panels).

quent signaling, we examined alterations of behavior and levels of phosphorylation of NR1, NR2B, and CREB in the spinal cord following spinal administration of MMP-9 in naive mice. A single dose of MMP-9 (0.4 pmol, i.t.) produced behavioral signs that were similar to the naloxone-precipitated morphine withdrawal (Fig. 8A). The overall scores increased to $35.4 \pm 2.51$ after MMP-9 treatment, which was significantly higher $(p<0.01)$ than the $19.6 \pm 3.33$ in the control treated with PBS. Of the nine monitored behavioral signs, scores for diarrhea, paw tremor, ptosis, tremor, and wet dog shakes increased significantly, while the others did not. In a separate group of mice, spinal administration of MMP-9 (0.4 pmol) produced significant mechanical allodynia tested in the hindpaws. The mechanical hypersensitivity developed within $1 \mathrm{~h}$, peaked at $2 \mathrm{~h}$, and lasted for at least $6 \mathrm{~h}$ (Fig. $8 \mathrm{~B}$ ). Meanwhile, the same treatment of MMP-9 significantly increased phosphorylation of NR1 and NR2B receptors and CREB (Fig. 8C). These results indicate that spinal MMP-9 can induce morphine withdrawal-like behavioral signs and activate NR1 and NR2B receptors and the downstream pathways.

A function-neutralizing antibody against integrin- $\beta 1$ prevents MMP-9-induced phosphorylation of NR1, NR2B, and CREB We investigated a potential role of integrin- $\beta 1$, which mediates MMP-9 regulation of synaptic plasticity and long-term potenti- ation in the spinal cord (Nagy et al., 2004), in mediating effects of MMP-9 on NR1 and NR2B receptors. First, our results showed that expression of integrin- $\beta 1$ in the spinal cord was markedly downregulated by morphine exposure and withdrawal (Fig. 9A). Expression of integrin- $\beta 1$ was also significantly downregulated by spinal administration of exogenous MMP-9 (0.4 pmol) (Fig. $9 B$ ). Further, $\beta 1 \mathrm{ab}$ ( $2 \mu \mathrm{g}$, i.t.) significantly suppressed MMP-9induced phosphorylation of NR1 and NR2B (Fig. 9C). These results suggest that integrin- $\beta 1$ is involved in MMP-9-induced phosphorylation of NR1 and NR2B receptors during morphine treatment.

Spinal inhibition of nNOS suppresses MMP-9 activity after morphine withdrawal

NO has been demonstrated to play an important role in opioid dependence (Pasternak, 2007) and directly activates MMP-9 in a model of cerebral ischemia (Gu et al., 2002). We used a selective nNOS inhibitor 7NI to reduce NO signaling and found that morphine withdrawal-induced MMP-9 activity in the spinal cord was significantly suppressed by spinal administration of 7NI (50 nmol, i.t., one dose before naloxone administration) (Fig. 10). This result supports a role of NO regulation of spinal MMP-9 in the development of morphine dependence. 


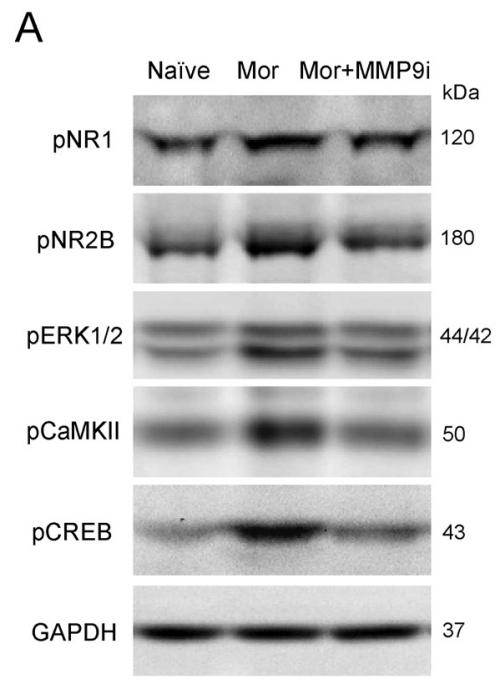

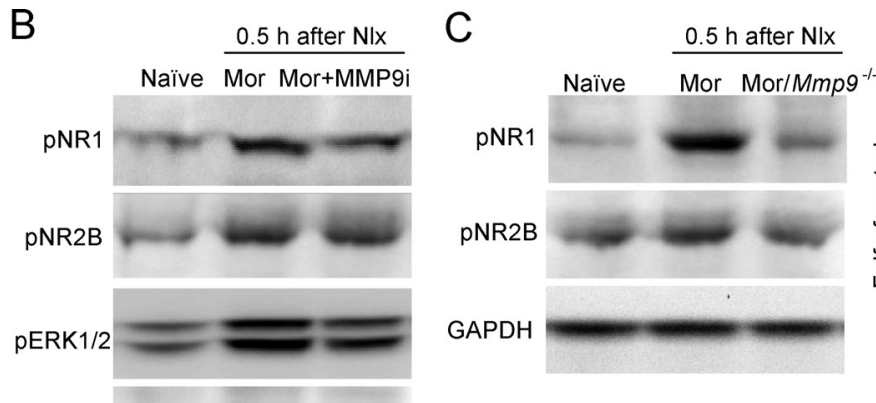
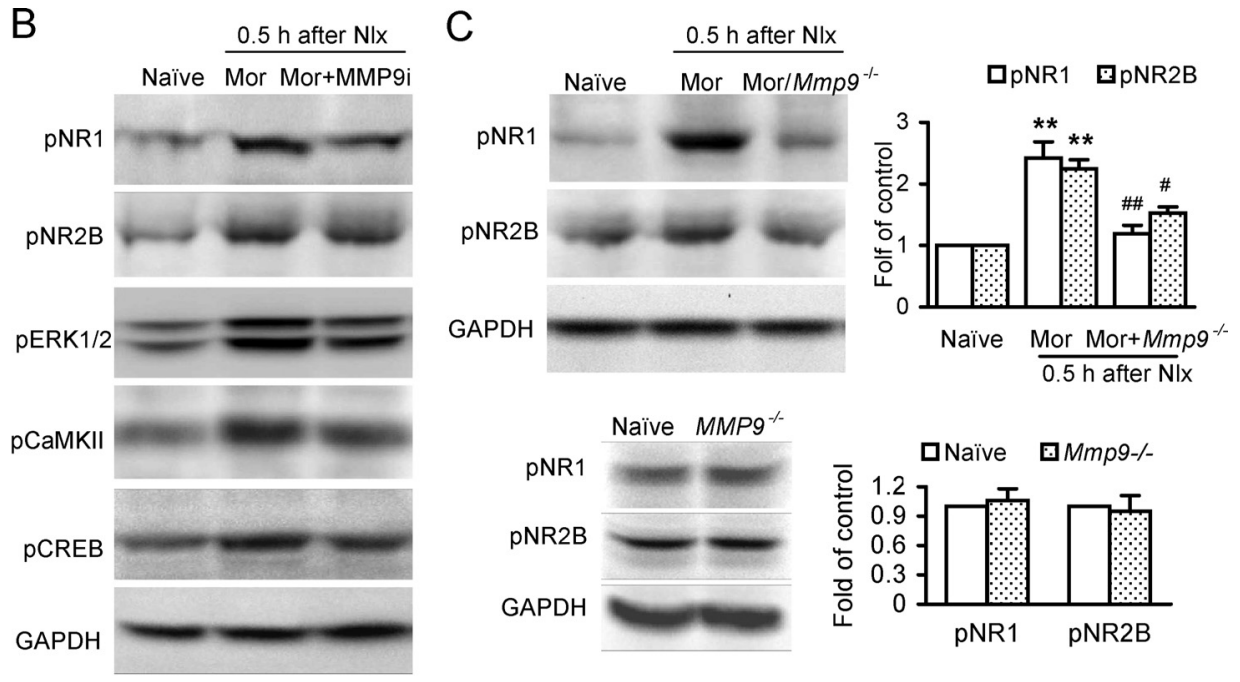
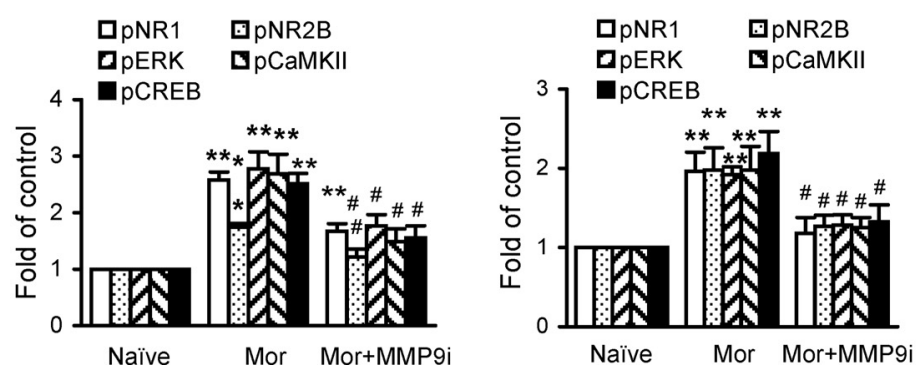

Figure 7. Inhibition of spinal MMP-9, but not MMP-2 or targeted mutation of MMP-9 suppresses increased phosphorylation of NR1, NR2B, ERK, CaMKII, and CREB in the spinal cord associated with morphine (Mor) exposure and naloxone (NIx)-precipitated withdrawal. $\boldsymbol{A}, \boldsymbol{B}$, Expression of phosphorylation of the molecules after treatment of Mor $(\boldsymbol{A})$ and Mor + NIx $(\boldsymbol{B})$ with MMP-9 inhibitor MMP9i. Top, Examples of Western blot; bottom, data summary ( $n=5$ each group). ${ }^{* *} p<0.01$ compared to naive; ${ }^{\#} p<0.05$ and ${ }^{\# \#} p<0.01$ compared to Mor. C, Expression of phosphorylation of pNR1 and pNR2B after treatment of Mor or (Mor + NIx) in Mmp9- / - mouse spinal cord ( $n=5$ each group). ${ }^{* *} p<0.01$ compared to naive; ${ }^{*} p<0.05$ and ${ }^{\# \#} p<0.01$ compared to WT. ${ }^{*} p<$ $0.05,{ }^{* *} p<0.01$ compared to naive. Bottom, Expression of NR1 and NR2B were not statistically different between naive and MMP9 $-/-$ groups; thus, naive was used as control.

\section{Effects of inhibiting spinal MMP-9 and MMP-2 on morphine tolerance}

Physical tolerance, a profound decrease in analgesic effect, is another major limitation to long-term use of morphine, in addition to physical dependence. We examined whether analgesic effects of morphine could be rescued by inhibiting spinal MMP-9 or MMP-2. MMP9i and MMP2i (each $5 \mu$ g, i.t., 30 min before the dose of morphine at $100 \mathrm{mg} / \mathrm{kg}$ ), respectively, significantly reduced the decrease in analgesic effect of morphine at $10 \mathrm{mg} / \mathrm{kg}$, which was administered $24 \mathrm{~h}$ after a treatment of morphine at 100 $\mathrm{mg} / \mathrm{kg}$ (protocol Mor100-10) (Fig. 11A). To mimic long-term, clinical uses of morphine at high doses, we tested the analgesic effect of morphine at $10 \mathrm{mg} / \mathrm{kg}$ followed by repetitive morphine at $50 \mathrm{mg} / \mathrm{kg} 2 \mathrm{~h}$ afterward, for 7 consecutive days (protocol Mor10-50). MMP9i, but not MMP2i, rescued the analgesic effect of morphine during the test days 3 through 7 (Fig. $11 B$ ). However, neither MMP9i nor MMP2i significantly changed the tolerance following repetitive injection of morphine at $10 \mathrm{mg} / \mathrm{kg}$ given daily for 7 consecutive days (protocol Mor 10), although MMP9i showed a tendency to reduce tolerance during days 5-7 (Fig. $11 C)$. Further, Western blot analysis showed that expression of MMP-9 was significantly increased following morphine treatment using protocol Mor10-50, but not that using protocol Mor10. Expression of MMP-2 was not changed by morphine treatment using either protocol Mor10-50 or Mor10 (Fig. 11D).

\section{Discussion}

Our study reveals a critical role for gelatinase MMP-9 in development of physical dependence on morphine. Spinal neuronal
MMP-9 can induce activation of NR1 and NR2B receptors and the downstream pathways in addition to the behavioral and neurochemical signs of morphine dependence and withdrawal. These actions of MMP- 9 are regulated by integrin- $\beta 1$ and NO in the spinal cord. It provides a novel mechanism underlying morphine physical dependence and suggests that inhibition of MMP-9 signaling may be of potential clinical benefit in preventing, minimizing, or reversing morphine-induced physical dependence and other side effects, thereby facilitating the clinical utility of opioid drugs.

MMP-9 and MMP-2 are expressed in the brain and spinal cord, and are often increased in response to inflammation, injury, or neurological diseases (Yong et al., 2001; Kawasaki et al., 2008). Analysis of the cellular distribution of MMP-9 and MMP-2 has revealed that MMP-9, but not MMP-2, increases both in neurons and astrocytes in the rat hippocampus following intraperitoneal kainate administration (Szklarczyk et al., 2002) and in DRG neurons after spinal nerve ligation (Kawasaki et al., 2008), while MMP-2 activity increases in astrocytes in the DH (Kawasaki et al., 2008). The present study demonstrates that morphine exposure and withdrawal increase spinal activity of MMP-9, but not MMP-2. The increased MMP-9 activity occurs mainly in the superficial layers of the $\mathrm{DH}$, an essential area for generation and processing of pain signals, and colocalizes primarily with neurons and, to a lesser extent, with astrocytes and microglia. In the spinal nerve injury model, MMP-9 was found colocalized with DRG neurons and CGRP primary afferents, suggesting that the spinal MMP-9 derives primarily from axonal transport from DRG 


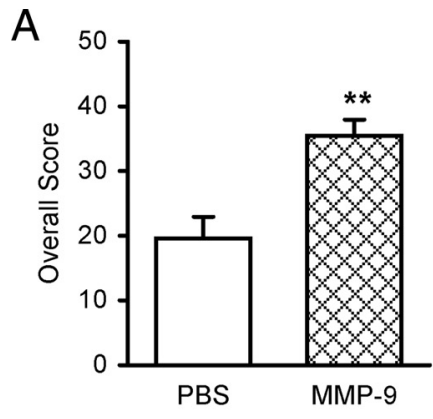

B

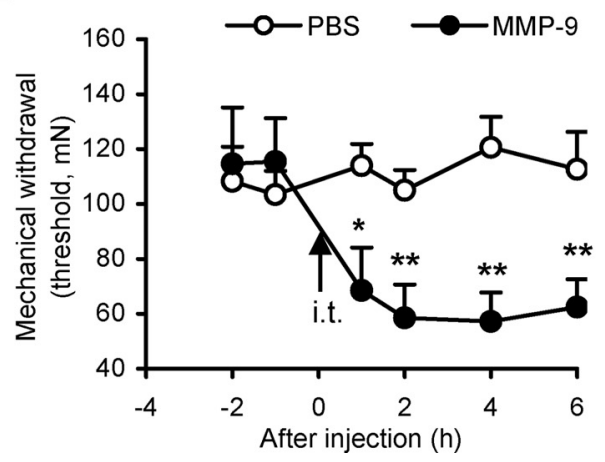

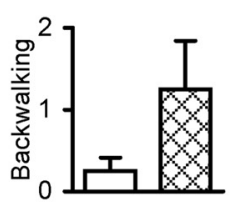
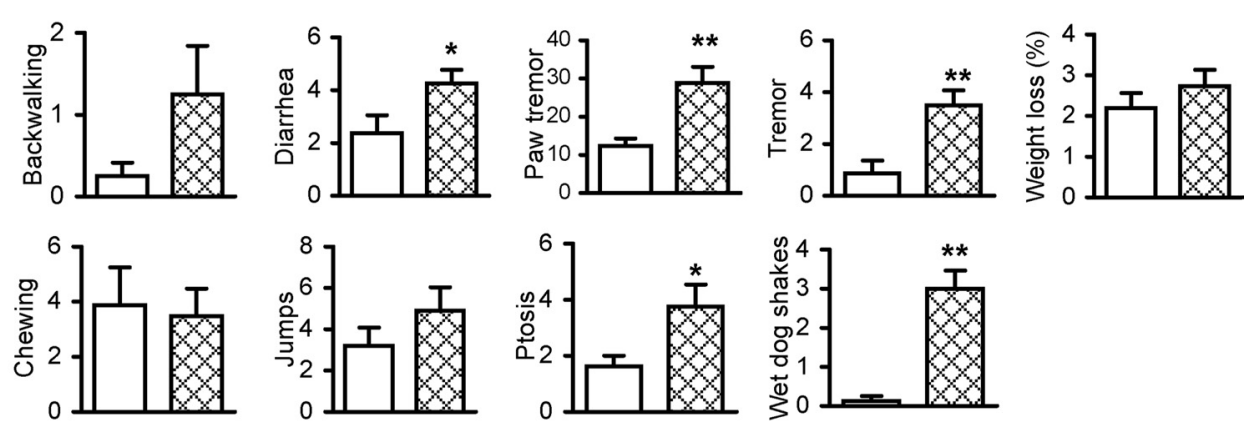

C

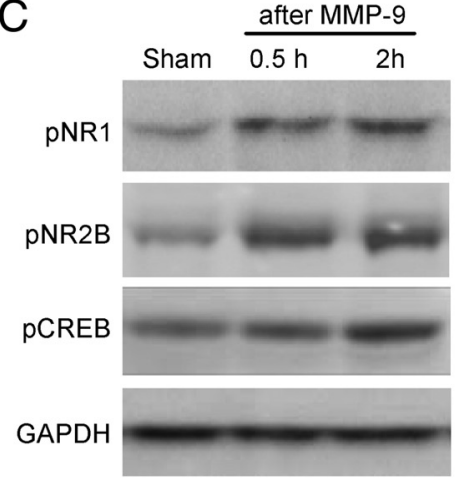

Figure 8. Spinal administration of exogenous MMP-9 causes morphine withdrawal-like behavioral signs, mechanical allodynia, and increases in phosphorylation of NR1, NR2B, and CREB in the spinal cord. $\boldsymbol{A}$, Morphine withdrawal-like behavioral signs induced by MMP-9 (0.4 pmol, i.t.). PBS was injected as vehicle control. Ten mice were included in each group. $\boldsymbol{B}$, Mechanical allodynia induced by MMP-9 (0.4 pmol, i.t.). Data presented are averages of both hindpaws in both hindpaws. C, Increased phosphorylation of NR1, NR2B, and CREB in the spinal cord after MMP-9 treatment. Left, Examples; right, data summary. Four spinal cords were included in each group. ${ }^{*} p<0.05,{ }^{* *} p<0.01$ compared to PBS $(\boldsymbol{A}, \boldsymbol{B})$ or sham $(\boldsymbol{C})$.
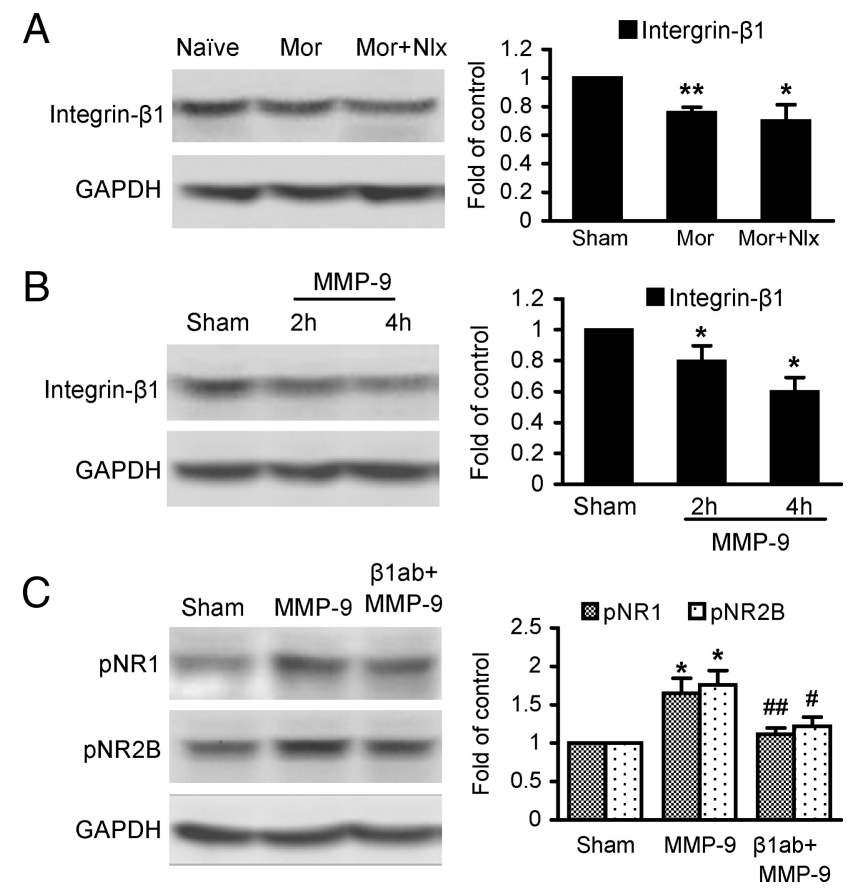

Figure 9. Interactions among MMP-9, NR1, and NR2B receptors and integrin- $\beta 1$ in the spinal cord. $\boldsymbol{A}$, Morphine exposure and naloxone precipitated-withdrawal-induced downregulation of integrin- $\beta 1$. $\boldsymbol{B}$, Spinal administration of exogenous MMP-9 $(0.4 \mathrm{pmol})$ induced downregulation of integrin- $\beta 1$. C, $\beta 1 \mathrm{ab}(2 \mu \mathrm{g}$, i.t.) reduced MMP-9 ( $2 \mathrm{~h}$ )-induced upregulation of NR1 and NR2B. Four spinal cords were assayed in each group. ${ }^{*} p<0.05$, ${ }^{* *} p<0.01$ compared to the corresponding group of sham $(\boldsymbol{A}-\boldsymbol{C}) ;{ }^{\#} p<0.05,{ }^{\# \#} p<0.01$ compared to MMP-9 (C).

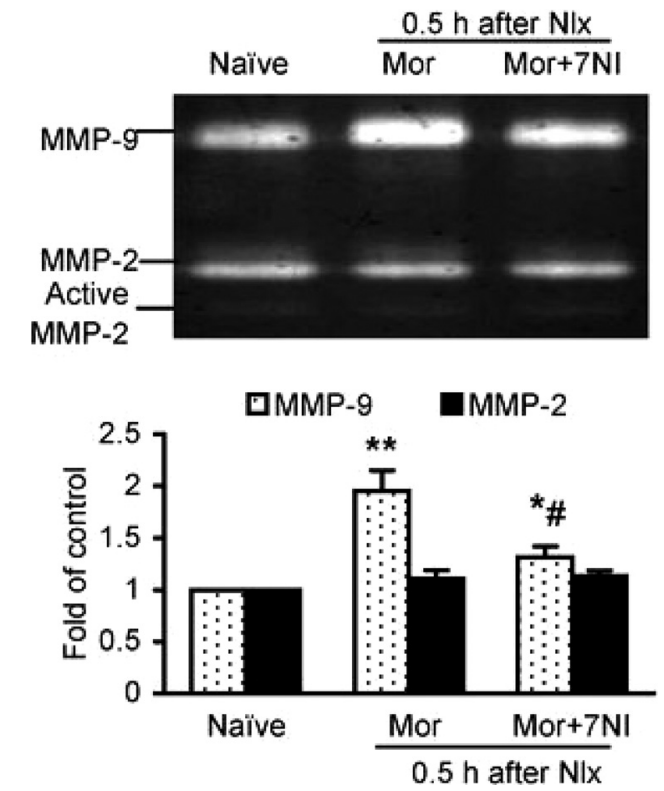

Figure 10. Spinal administration of an $\mathrm{nNOS}$ inhibitor $7 \mathrm{NI}$ attenuates the increased activity of MMP-9 after naloxone (NIx)-precipitated morphine (Mor) withdrawal. Activity of MMP-2 was altered by neither Mor nor 7NI treatment. Top, Gelatin zymography showing activity of MMP-9 and MMP-2 in the spinal cord ( $n=6$ each group). Bottom, Data summary. ${ }^{*} p<0.05$ and ${ }^{* *} p<0.01$ compared to naive. ${ }^{\#} p<0.05$ compared to the corresponding Mor group.

neurons (Kawasaki et al., 2008). However, in the present study MMP-9 was colocalized with neither IB4 nor CGRP primary afferents within the DH after morphine treatment; the upregulated MMP-9 following morphine treatment was found primarily in neurons in the $\mathrm{DH}$ and in some astrocytes and microglia. In 

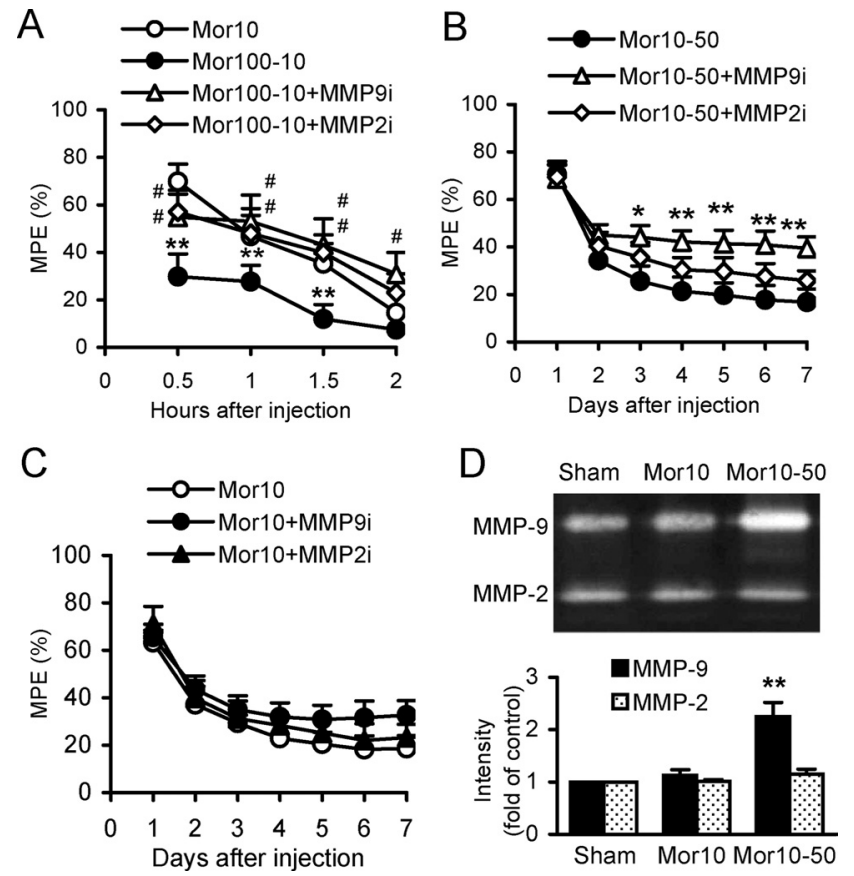

Figure 11. Effects of spinal inhibition of MMP-9 and MMP-2 on morphine tolerance. A, Acute tolerance measured after morphine (Mor) at $10 \mathrm{mg} / \mathrm{kg}$ (s.c.) alone (Mor10) and $24 \mathrm{~h}$ after Mor at $100 \mathrm{mg} / \mathrm{kg}$ (protocol Mor100-10). MMP9i and MMP2i were administered (intrathecally), respectively, $30 \mathrm{~min}$ before the dose of Mor at $100 \mathrm{mg} / \mathrm{kg} .{ }^{*} p<0.05$, ${ }^{* *} p<0.01$ compared to the control group Mor 10. ${ }^{\#} p<0.05,{ }^{\# \#} p<0.01$ compared to the model group Mor100-10. Ten mice were included in each group. $\boldsymbol{B}$, Tolerance measured after Mor at $10 \mathrm{mg} / \mathrm{kg}$ (s.c.) followed by repetitive treatment of Mor at $50 \mathrm{mg} / \mathrm{kg} 2 \mathrm{~h}$ afterward each day for 7 consecutive days (protocol Mor10-50). MMP9i and MMP2i were administered, respectively, immediately after Mor (50 mg/kg) injection. ${ }^{*} p<0.05,{ }^{* *} p<0.01$ compared to the group of Mor10-50. Number of mice: Mor10-50 $=10$, Mor10-50 + MMP9i $=15$, Mor10-50 + MMP2i $=15$. C, Tolerance following repetitive treatment of Mor at $10 \mathrm{mg} / \mathrm{kg}$ given daily for $7 \mathrm{~d}$ (protocol Mor 10) with the analgesic effect measured 30 min after each injection. MMP9i or MMP2i was administered immediately after Mor injection. Fifteen mice were included in each group. $\boldsymbol{D}$, Upregulation of MMP-9, but not MMP-2, in the spinal cord following treatment of Mor10-50, but not Mor10. ${ }^{* *} p<0.01$ compared to the group of sham and Mor10.

contrast, our data demonstrate that spinal MMP-2 activity is not important for the development of morphine dependence, similar to its unimportance for kainate-induced excitotoxicity in the hippocampus (Szklarczyk et al., 2002). MMP-2 is, however, important for the maintenance of neuropathic pain caused by nerve injury (Kawasaki et al., 2008). Together, MMP-9 and MMP-2 activity may contribute differently to different pathological conditions. Patterns of expression of MMP-9 and MMP-2 in the hippocampus and the DH are similar to each other under conditions of morphine treatment and kainate-induced excitotoxicity (Szklarczyk et al., 2002). In the case of nerve injury, the initial spinal MMP-9 derives from axonal transport in DRG neurons (Kawasaki et al., 2008), while following morphine treatment in the spinal cord or kainate treatment in the hippocampus the initial MMP-9 may originate primarily locally, within central neurons (Szklarczyk et al., 2002).

NMDARs have a well established role in opiate-related neural plasticity. NMDAR activation results in $\mathrm{Ca}^{2+}$ influx through the NMDAR ion-channel complex (Mao and Mayer, 2001; Nestler, 2001; Inoue et al., 2003; Bajo et al., 2006). Subsequent activation of various $\mathrm{Ca}^{2+}$-dependent signaling enzymes, such as CaMKII, can phosphorylate CREB, leading to increases in c-Fos mRNA and c-Fos protein levels (Mao and Mayer, 2001; Nestler, 2001; Liu et al., 2009a,b). Gene expression is thought to play an impor-

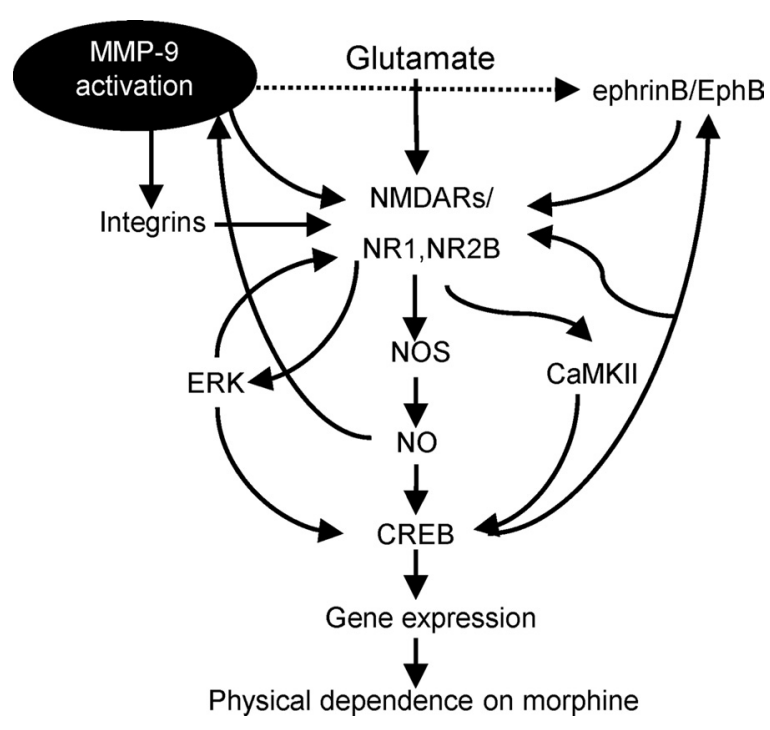

Figure 12. Model of spinal MMP-9 contributions to the development of physical dependence on morphine. Flowchart illustrates a functional link among MMP-9 activation, MMP-9dependent cellular responses, interactions between MMP-9 and integrins, NMDAR subunits NR1 and NR2B, ephrinB-EphB receptors, other intracellular signals, and behavioral manifestations of morphine dependence.

tant role in many forms of plasticity, including morphine dependence. Here we provide evidence that morphine exposure and withdrawal or spinal administration of exogenous MMP-9 increases the phosphorylation of NMDAR subunits, NR1 and NR2B, as well as CaMKII, ERK, and CREB, and induces c-Fos expression. These effects are prevented or suppressed by spinal inhibition or targeted mutation of MMP-9. Therefore, we hypothesize that MMP-9 in the DH may contribute to morphine dependence probably via interaction with the NR1 and NR2B receptors and therefore result in subsequent activation of $\mathrm{Ca}^{2+}$ dependent signaling pathways.

MMPs can influence dendritic spine development and hence synaptic stability in hippocampal neuron cultures, and can induce synapse modeling by interacting with NMDAR activity (Bilousova et al., 2006; Ethell and Ethell, 2007). MMP-9 may regulate synaptic plasticity and long-term potentiation through integrins (Nagy et al., 2004), possibly through the cleavage of laminin or other ECM components to expose otherwise inaccessible arginine-glycine-aspartic acid sites that can then induce integrin signaling (Ethell and Ethell, 2007). Integrin signaling has been shown to modulate NMDAR currents, control the structural remodeling of dendritic spines/synapses, and play an important role in hippocampal long-term potentiation (Bahr et al., 1997; Chavis and Westbrook, 2001; Lin et al., 2003; BernardTrifilo et al., 2005; Moeller et al., 2006; Shi and Ethell, 2006; Michaluk et al., 2009). Here we provide evidence that spinal administration of exogenous MMP-9 downregulates expression of integrin- $\beta 1$ while activating NR1 and NR2B receptors, in addition to producing morphine withdrawal-like behavioral signs and mechanical allodynia. Moreover, a function-neutralizing antibody against integrin- $\beta 1$ can suppress MMP-9-induced phosphorylation of NR1 and NR2B receptors. Interestingly, integrin- $\beta 1$ is also downregulated after morphine treatment. These findings support a role for integrin- $\beta 1$ in mediating MMP-9 modulation of NMDARs in morphine dependence in the spinal cord. Another signaling system with which MMP proteolysis may interact and therefore modulate NMDARs is the ephrin-Eph receptor pathway. EphrinB2 and EphB2 receptors 
are cleaved by MMPs in vitro and in cultured primary hippocampal neurons (Hattori et al., 2000; Georgakopoulos et al., 2006; Lin et al., 2008). We recently implicated a role for spinal ephrinBEphB in morphine dependence probably via modulation of NR2B (Liu et al., 2009a).

NO can $S$-nitrosylate a wide range of proteins, including NR1 and NR2 (Jaffrey et al., 2001). In addition, exposure of NO to superoxide generates peroxynitrite, which can nitrosylate tyrosine residues (Muscoli et al., 2007; Pasternak, 2007). In a stroke model of cerebral ischemia, colocalization of MMP-9 and nNOS was found in ischemic cortical neurons, where MMP-9 could be $S$-nitrosylated and activated by NO (Gu et al., 2002). The present study shows that an nNOS inhibitor suppresses morphine exposure/withdrawal-induced upregulation of MMP-9. These findings indicate that free radicals may regulate MMP-9 activity during morphine treatment and cerebral ischemia. In addition, MMPs in the nucleus accumbens may be involved in methamphetamine-induced behavioral sensitization and reward by regulating dopamine release and receptor signaling (Mizoguchi et al., 2007a,b), and ECM remodeling in the hippocampus may be a persisting effect of chronic abuse that contributes to the compulsive and relapsing nature of cocaine addiction (Mash et al., 2007). The first demonstration of an opioid-mediated regulation of metalloproteinase activity was reported in cultured rat mesangial cells, in which morphine decreased $72 \mathrm{kDa}$ metalloproteinase activity (Sagar et al., 1994).

In addition to physical dependence, another major limitation to the long-term use of opiates is the development of physiological tolerance. We here show that the acute morphine tolerance can be markedly improved by inhibiting spinal MMP-9 or MMP-2; the chronic tolerance following repetitive treatment of morphine at higher doses $(10 \mathrm{mg} / \mathrm{kg}+50 \mathrm{mg} / \mathrm{kg})$, but not that at $10 \mathrm{mg} / \mathrm{kg}$ only, can be markedly improved by inhibiting MMP-9, but not MMP-2. Further, lack of MMP-9 and MMP-2 activity in response to repetitive morphine at $10 \mathrm{mg} / \mathrm{kg}$ may explain, at least partly, the failure of spinal inhibition of MMP-9 or MMP-2 in rescuing the analgesic effect of morphine. These results suggest a complexity of mechanisms underlying morphine tolerance. Such a complexity and potentially different roles of MMP-9 in morphine dependence and tolerance need to be further investigated. Possible pathways by which MMP-9 in the spinal cord may contribute to morphine dependence are illustrated in Figure 12.

\section{References}

Bahr BA, Staubli U, Xiao P, Chun D, Ji ZX, Esteban ET, Lynch G (1997) Arg-Gly-Asp-Ser-selective adhesion and the stabilization of long-term potentiation: pharmacological studies and the characterization of a candidate matrix receptor. J Neurosci 17:1320-1329.

Bailey CP, Connor M (2005) Opioids: cellular mechanisms of tolerance and physical dependence. Curr Opin Pharmacol 5:60-68.

Bajo M, Crawford EF, Roberto M, Madamba SG, Siggins GR (2006) Chronic morphine treatment alters expression of N-methyl-D-aspartate receptor subunits in the extended amygdala. J Neurosci Res 83:532-537.

Barrot M, Olivier JD, Perrotti LI, DiLeone RJ, Berton O, Eisch AJ, Impey S, Storm DR, Neve RL, Yin JC, Zachariou V, Nestler EJ (2002) CREB activity in the nucleus accumbens shell controls gating of behavioral responses to emotional stimuli. Proc Natl Acad Sci U S A 99:11435-11440.

Bernard-Trifilo JA, Kramár EA, Torp R, Lin CY, Pineda EA, Lynch G, Gall CM (2005) Integrin signaling cascades are operational in adult hippocampal synapses and modulate NMDA receptor physiology. J Neurochem 93:834-849.

Bilousova TV, Rusakov DA, Ethell DW, Ethell IM (2006) Matrix metalloproteinase-7 disrupts dendritic spines in hippocampal neurons through NMDA receptor activation. J Neurochem 97:44-56.

Bundesen LQ, Scheel TA, Bregman BS, Kromer LF (2003) Ephrin-B2 and
EphB2 regulation of astrocyte-meningeal fibroblast interactions in response to spinal cord lesions in adult rats. J Neurosci 23:7789-7800.

Chattopadhyay S, Myers RR, Janes J, Shubayev V (2007) Cytokine regulation of MMP-9 in peripheral glia: implications for pathological processes and pain in injured nerve. Brain Behav Immun 21:561-568.

Chavis P, Westbrook G (2001) Integrins mediate functional pre- and postsynaptic maturation at a hippocampal synapse. Nature 411:317-321.

Ethell IM, Ethell DW (2007) Matrix metalloproteinases in brain development and remodeling: synaptic functions and targets. J Neurosci Res 85:2813-2823.

Gasche Y, Fujimura M, Morita-Fujimura Y, Copin JC, Kawase M, Massengale J, Chan PH (1999) Early appearance of activated matrix metalloproteinase-9 after focal cerebral ischemia in mice: a possible role in blood-brain barrier dysfunction. J Cereb Blood Flow Metab 19:1020-1028.

Georgakopoulos A, Litterst C, Ghersi E, Baki L, Xu C, Serban G, Robakis NK (2006) Metalloproteinase/Presenilin1 processing of ephrinB regulates EphB-induced Src phosphorylation and signaling. EMBO J 25:12421252.

Gu Z, Kaul M, Yan B, Kridel SJ, Cui J, Strongin A, Smith JW, Liddington RC, Lipton SA (2002) S-nitrosylation of matrix metalloproteinases: signaling pathway to neuronal cell death. Science 297:1186-1190.

Han Y, Song XS, Liu WT, Henkemeyer M, Song XJ (2008) Targeted mutation of EphB1 receptor prevents development of neuropathic hyperalgesia and physical dependence on morphine in mice. Mol Pain 4:60.

Hattori M, Osterfield M, Flanagan JG (2000) Regulated cleavage of a contact-mediated axon repellent. Science 289:1360-1365.

Inoue M, Mishina M, Ueda $\mathrm{H}$ (2003) Locus-specific rescue of GluR $\varepsilon 1$ NMDA receptors in mutant mice identifies the brain regions important for morphine tolerance and dependence. J Neurosci 23:6529-6536.

Jaffrey SR, Erdjument-Bromage H, Ferris CD, Tempst P, Snyder SH (2001) Protein S-nitrosylation: a physiological signal for neuronal nitric oxide. Nat Cell Biol 3:193-197.

Jhamandas KH, Marsala M, Ibuki T, Yaksh TL (1996) Spinal amino acid release and precipitated withdrawal in rats chronically infused with spinal morphine. J Neurosci 16:2758-2766.

Kawasaki Y, Xu ZZ, Wang X, Park JY, Zhuang ZY, Tan PH, Gao YJ, Roy K, Corfas G, Lo EH, Ji RR (2008) Distinct roles of matrix metalloproteases in the early- and late-phase development of neuropathic pain. Nat Med 14:331-336.

Kolesnikov YA, Pick CG, Ciszewska G, Pasternak GW (1993) Blockade of tolerance to morphine but not to kappa opioids by a nitric oxide synthase inhibitor. Proc Natl Acad Sci U S A 90:5162-5166.

Liang D, Li X, Clark JD (2004) Increased expression of Ca2+/calmodulindependent protein kinase II alpha during chronic morphine exposure. Neuroscience 123:769-775.

Lin B, Arai AC, Lynch G, Gall CM (2003) Integrins regulate NMDA receptor-mediated synaptic currents. J Neurophysiol 89:2874-2878.

Lin KT, Sloniowski S, Ethell DW, Ethell IM (2008) Ephrin-B2-induced cleavage of EphB2 receptor is mediated by matrix metalloproteinases to trigger cell repulsion. J Biol Chem 283:28969-28979.

Liu WT, Li HC, Song XS, Huang ZJ, Song XJ (2009a) EphB receptor signaling in mouse spinal cord contributes to physical dependence on morphine. FASEB J 23:90-98.

Liu WT, Han Y, Li HC, Adams B, Zheng JH, Wu YP, Henkemeyer M, Song XJ (2009b) An in vivo mouse model of long-term potentiation at synapses between primary afferent $C$-fibers and spinal dorsal horn neurons: essential role of EphB1 receptor. Mol Pain 5:29.

Lu L, Zeng S, Liu D, Ceng X (2000) Inhibition of the amygdala and hippocampal calcium/calmodulin-dependent protein kinase II attenuates the dependence and relapse to morphine differently in rats. Neurosci Lett 291:191-195.

Mao J, Mayer DJ (2001) Spinal cord neuroplasticity following repeated opioid exposure and its relation to pathological pain. Ann N Y Acad Sci 933:175-184.

Mash DC, ffrench-Mullen J, Adi N, Qin Y, Buck A, Pablo J (2007) Gene expression in human hippocampus from cocaine abusers identifies genes which regulate extracellular matrix remodeling. PLoS One 2:e1187.

Michaluk P, Mikasova L, Groc L, Frischknecht R, Choquet D, Kaczmarek L (2009) Matrix metalloproteinase-9 controls NMDA receptor surface diffusion through integrin $\beta 1$ signaling. J Neurosci 29:6007-6012.

Mizoguchi H, Yamada K, Mouri A, Niwa M, Mizuno T, Noda Y, Nitta A, Itohara S, Banno Y, Nabeshima T (2007a) Role of matrix metallopro- 
teinase and tissue inhibitor of MMP in methamphetamine-induced behavioral sensitization and reward: implications for dopamine receptor down-regulation and dopamine release. J Neurochem 102:1548-1560.

Mizoguchi H, Yamada K, Niwa M, Mouri A, Mizuno T, Noda Y, Nitta A, Itohara S, Banno Y, Nabeshima T (2007b) Reduction of methamphetamineinduced sensitization and reward in matrix metalloproteinase-2 and -9deficient mice. J Neurochem 100:1579-1588.

Moeller ML, Shi Y, Reichardt LF, Ethell IM (2006) EphB receptors regulate dendritic spine morphogenesis through the recruitment/phosphorylation of focal adhesion kinase and RhoA activation. J Biol Chem 281:1587-1598.

Muscoli C, Cuzzocrea S, Ndengele MM, Mollace V, Porreca F, Fabrizi F, Esposito E, Masini E, Matuschak GM, Salvemini D (2007) Therapeutic manipulation of peroxynitrite attenuates the development of opiateinduced antinociceptive tolerance in mice. J Clin Invest 117:3530-3539.

Nagy GG, Watanabe M, Fukaya M, Todd AJ (2004) Synaptic distribution of the NR1, NR2A and NR2B subunits of the N-methyl-d-aspartate receptor in the rat lumbar spinal cord revealed with an antigen-unmasking technique. Eur J Neurosci 20:3301-3312.

Nestler EJ (2001) Molecular basis of long-term plasticity underlying addiction. Nat Rev Neurosci 2:119-128.

Overall CM, López-Otín C (2002) Strategies for MMP inhibition in cancer: innovations for the post-trial era. Nat Rev Cancer 2:657-672.

Parks WC, Wilson CL, López-Boado YS (2004) Matrix metalloproteinases as modulators of inflammation and innate immunity. Nat Rev Immunol 4:617-629.

Pasternak GW (2007) When it comes to opiates, just say NO. J Clin Invest 117:3185-3187.

Pasternak GW, Kolesnikov Y (2005) The NMDA/nitric oxide synthase cascade in opioid analgesia and tolerance. In: Contemporary clinical neuroscience: glutamate and addiction (Herman BH, ed), pp 409-416. Totowa, NJ: Humana.

Ren X, Noda Y, Mamiya T, Nagai T, Nabeshima T (2004) A neuroactive steroid, dehydroepiandrosterone sulfate, prevents the development of morphine dependence and tolerance via c-fos expression linked to the extracellular signal-regulated protein kinase. Behav Brain Res 152:243250.

Sagar S, Sorbi D, Arbeit LA, Singhal PC (1994) Morphine modulates 72-kDa matrix metalloproteinase. Am J Physiol 267:F654-F659.

Shaw-Lutchman TZ, Barrot M, Wallace T, Gilden L, Zachariou V, Impey S, Duman RS, Storm D, Nestler EJ (2002) Regional and cellular mapping of cAMP response element-mediated transcription during naltrexoneprecipitated morphine withdrawal. J Neurosci 22:3663-3672.

Shi Y, Ethell IM (2006) Integrins control dendritic spine plasticity in hippocampal neurons through NMDA receptor and $\mathrm{Ca}^{2+} /$ calmodulindependent protein kinase II-mediated actin reorganization. J Neurosci 26:1813-1822.

Szklarczyk A, Lapinska J, Rylski M, McKay RD, Kaczmarek L (2002) Matrix metalloproteinase-9 undergoes expression and activation during dendritic remodeling in adult hippocampus. J Neurosci 22:920-930.

Wang X, Jung J, Asahi M, Chwang W, Russo L, Moskowitz MA, Dixon CE, Fini ME, Lo EH (2000) Effects of matrix metalloproteinase-9 gene knock-out on morphological and motor outcomes after traumatic brain injury. J Neurosci 20:7037-7042.

Yong VW (2005) Metalloproteinases: mediators of pathology and regeneration in the CNS. Nat Rev Neurosci 6:931-944.

Yong VW, Power C, Forsyth P, Edwards DR (2001) Metalloproteinases in biology and pathology of the nervous system. Nat Rev Neurosci 2:502-511.

Zachariou V, Georgescu D, Sanchez N, Rahman Z, DiLeone R, Berton O, Neve RL, Sim-Selley LJ, Selley DE, Gold SJ, Nestler EJ (2003) Essential role for RGS9 in opiate action. Proc Natl Acad Sci U S A 100:13656-13661.

Zhao BQ, Wang S, Kim HY, Storrie H, Rosen BR, Mooney DJ, Wang X, Lo EH (2006) Role of matrix metalloproteinases in delayed cortical responses after stroke. Nat Med 12:441-445. 